\title{
BODY CHOLESTEROL METABOLISM IN MAN. II. MEASUREMENT OF THE BODY CHOLESTEROL MISCIBLE POOL AND TURNOVER RATE* +
}

\author{
BY ARAM V. CHOBANIAN, $\$$ BELTON A. BURROWS AND WILLIAM HOLLANDER § \\ WITH THE TECHNICAL ASSISTANCE OF MARGARET SULLIVAN AND \\ MARILYN COLOMBO \\ (From the Robert Dawson Evans Memorial, Department of Clinical Research, Massachusetts \\ Memorial Hospitals, and the Department of Medicine, Boston University \\ School of Medicine, Boston, Mass.)
}

(Submitted for publication March 1, 1962; accepted May 17, 1962)

The measurement of serum cholesterol, with which the major part of the clinical literature on cholesterol is concerned, represents only one facet of the body metabolism of cholesterol. Hence, methods of measuring the metabolism of cholesterol in the body tissues of man would undoubtedly be useful. Over the past few years, techniques utilizing labeled isotopes have been developed to measure the body miscible pool of a variety of substances, including sodium, potassium, water, and uric acid $(1,2)$. But the ability to measure a miscible pool of cholesterol by isotope dilution principles has been questioned as a result of studies indicating that the disappearance of labeled cholesterol from the plasma proceeds at a series of decreasing exponential rates (rather than a single rate) for periods of as long as 50 days (3). However, when the curve for disappearance from plasma of $\mathrm{C}^{14}$-cholesterol specific radioactivity is followed for periods ranging from 4 to 7 months, as has been done in this investigation as well as in another recently reported study (4), it is evident that the plasma cholesterol specific activity eventually does decline at an exponential rate, suggesting that a body cholesterol miscible pool and turnover rate may be determined from these curves. Furthermore, post-mortem tissue studies in patients who have died at vary-

* This work was supported in part by Grant PHS-H1536(C8) from the National Heart Institute, by Grant AT-(30-1)919 from the Atomic Energy Commission, and in part by a grant from Mr. U. A. Whitaker.

† Submitted in honor of Chester S. Keefer, M.D., and the Golden Anniversary of the Evans Memorial Department of Clinical Research, Boston, Mass.

$\ddagger$ A portion of this work was done on a Postdoctoral Fellowship of the National Heart Institute.

$\S$ Special Research Fellow, National Institutes of Health. ing intervals after receiving $\mathrm{C}^{\mathbf{1 4}}$-cholesterol have indicated that a miscible tissue pool of cholesterol that is exchangeable with the serum cholesterol does exist in man (5). These observations have been utilized to measure and compare the body cholesterol miscible pools and turnover rates in a group of normal and hypercholesterolemic individuals by following the rate of disappearance of labeled cholesterol from the plasma for 4 to 7 months after its intravenous administration.

\section{MATERIAL AND METHODS}

Five normal ambulatory subjects with serum cholesterol levels less than $250 \mathrm{mg}$ per $100 \mathrm{ml}$ and seven ambulatory patients with hypercholesterolemia were included in the study. The hypercholesterolemia in two of the patients was associated with the nephrotic syndrome. One hypercholesterolemic patient had clinical and laboratory signs of myxedema which had been induced by propylthiouracil therapy for severe angina pectoris, and one other patient had familial hypercholesterolemia with xanthomatoses and coronary heart disease. The remaining three patients with hypercholesterolemia also had coexistent essential hypertension. All patients selected for the study had relatively stable serum cholesterol levels with variations from the mean not greater than 10 per cent during the course of these studies. The dietary intake was unrestricted throughout the period of investigation.

Tracer doses of 5 to $30 \mu \mathrm{c}$ of $4-\mathrm{C}^{14}$-cholesterol with a specific activity of $37.7 \mu \mathrm{c}$ per $\mathrm{mg}$ were administered intravenously to all subjects according to methods previously described (5). Samples of venous blood were collected at 1- to 10-day intervals over a total period of 125 to 212 days after administration of the labeled cholesterol. The plasma was separated from the red blood cells and analyzed for free and total cholesterol content and radioactivity as previously described (5). The free and ester cholesterol specific activities were calculated from these values. In two of the subjects these studies were repeated 12 and 14 months after the initial in- 
TABLE I

Experimental results*

\begin{tabular}{|c|c|c|c|c|c|c|c|c|c|}
\hline \multirow{2}{*}{$\begin{array}{l}\text { Patient } \\
\text { Sex } \\
\text { Age }\end{array}$} & \multirow[b]{2}{*}{ Weight } & \multirow[b]{2}{*}{ BSA } & \multirow[b]{2}{*}{ Diagnosis } & \multirow[b]{2}{*}{$\begin{array}{l}\text { Serum } \\
\text { chol. }\end{array}$} & \multirow[b]{2}{*}{$\mathbf{t}_{1}$ chol. } & \multicolumn{3}{|c|}{ Eohol } & \multirow{2}{*}{ 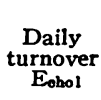 } \\
\hline & & & & & & $\mathbf{g}$ & $\stackrel{\mathrm{g} / \mathrm{m}^{2}}{\mathrm{BSA}}$ & Body wt & \\
\hline A.T. $\sigma^{7} 26$ & $\begin{array}{c}k g \\
75.4\end{array}$ & $\begin{array}{c}m^{2} \\
1.99\end{array}$ & Normal & $\begin{array}{l}m g \% \\
186\end{array}$ & $\begin{array}{l}\text { days } \\
59\end{array}$ & 134 & 67 & 0.18 & $\begin{array}{r}\text { g/day } \\
1.57\end{array}$ \\
\hline P.S. व $\sigma^{7} 29$ & 73.1 & 1.89 & Normal & 213 & 58 & 154 & 82 & 0.21 & 1.84 \\
\hline R.L. $\odot 45$ & 56.8 & 1.60 & Normal & 231 & 74 & 148 & 93 & 0.26 & 1.39 \\
\hline A.C. $\odot 56$ & 85.0 & 1.98 & Normal & 239 & 61 & 213 & 108 & 0.25 & 2.42 \\
\hline H.S. ơ 59 & 124.1 & 2.54 & Normal & 249 & 75 & 349 & 137 & 0.28 & 3.22 \\
\hline H.L. $९ 48 †$ & 65.8 & 1.67 & Essent. hyp., angina pect. & 285 & 62 & 201 & 120 & 0.31 & 2.25 \\
\hline R.M. $९ 54 \dagger$ & 64.1 & 1.69 & Essent. hyp. & 306 & 82 & 208 & 123 & 0.32 & 1.76 \\
\hline L.D. $\& 56$ & 73.8 & 1.74 & Essent. hyp. & 331 & 76 & 221 & 127 & 0.30 & 2.01 \\
\hline E.C. $\& 73$ & 55.6 & 1.51 & $\begin{array}{l}\text { Myxedema, } 2^{\circ} \text { propylthiouracil, } \\
\text { angina pectoris }\end{array}$ & 364 & 100 & 152 & 101 & 0.27 & 1.05 \\
\hline E.D. $\sigma^{7} 41$ & 73.3 & 1.85 & $\begin{array}{l}\text { Famil. hypercholest., xanthel- } \\
\text { asmata, angina pect. }\end{array}$ & 381 & 67 & 256 & 138 & 0.35 & 2.65 \\
\hline C.M. $\& 26$ & 66.9 & 1.68 & $\begin{array}{l}\text { Nephrotic synd., chronic } \\
\text { glomeruloneph. }\end{array}$ & 428 & 69 & 125 & 74 & 0.19 & 1.26 \\
\hline \multirow[t]{4}{*}{ A.M. व' 35} & 74.2 & 1.79 & $\begin{array}{l}\text { Nephrotic synd., chronic } \\
\text { glomeruloneph. }\end{array}$ & 534 & 76 & 201 & 112 & 0.27 & 1.83 \\
\hline & & & Mean & 312 & 71.6 & 197 & 107 & 0.27 & 1.68 \\
\hline & & & SD & \pm 101 & \pm 11.8 & \pm 62 & \pm 23.8 & \pm 0.05 & \pm 0.98 \\
\hline & & & $\mathrm{SE}$ & \pm 29.2 & \pm 3.43 & \pm 18 & \pm 7.2 & \pm 0.01 & \pm 0.28 \\
\hline
\end{tabular}

* BSA $=$ body surface area, $\mathrm{t}_{\mathrm{z}}=$ half-time disappearance of cholesterol, $\mathrm{E}_{\mathrm{ohol}}=$ miscible or exchangeable cholesterol, and daily turnover $=\left(0.693 / t_{l}\right)$ Eohol.

$t$ Values are the means of two determinations.

jection of $\mathrm{C}^{\mathbf{1 4}}$-cholesterol. In the patient with familial hypercholesterolemia and xanthomatoses, xanthelasmata were surgically removed 62 days after administration of $\mathrm{C}^{14}$-cholesterol and the $\mathrm{C}^{14}$-cholesterol specific activity of the xanthelasmata was determined.

In two of the subjects, complete stool collections were made over periods of 65 and 72 days, respectively, and complete urine collections over 15 days. The urine collections were terminated after 15 days, since no $\mathrm{C}^{14}$ radioactivity was measurable in the urine after the first week of study. All stools were collected in cardboard containers, weighed, and then frozen. Pooled samples representing 3 - to 5-day collection periods were homogenized in ethanol in a Waring Blendor and duplicate aliquots of the homogenate were extracted three times with ethanol; 1 - to 2-ml aliquots of the extract were layered in planchets which were then dried and weighed. The total $\mathrm{C}^{14}$ content of the stool samples was determined in a windowless gas-flow counter with apptopriate corrections for absorption.
Duplicate 5-ml aliquots of each 24-hour urine collection were decolorized with activated charcoal and analyzed for total $\mathrm{C}^{14}$ radioactivity in a Tri-Carb liquid scintillation spectrometer after addition of $15 \mathrm{ml}$ of scintillation solution. ${ }^{1}$

\section{RESULTS}

A summary and statistical analysis of the results are tabulated in Tables I and II.

1. Rate of disappearance of $C^{14}$-cholesterol from the serum. The plasma disappearance curve of free and ester $\mathrm{C}^{14}$-cholesterol specific activity of a representative subject is illustrated in Figure 1.

1 Prepared as follows: $4.0 \mathrm{~g}$ of 2,5-diphenyloxazole (PPO), $0.25 \mathrm{~g}$ of 1,4-di-2-(5-phenyloxazolyl)-benzene (POPOP), and $50.0 \mathrm{~g}$ naphthalene were made up to $1 \mathrm{~L}$ with $p$-dioxane.

TABLE II

Statistical correlation *

\begin{tabular}{|c|c|c|c|c|c|}
\hline & $\begin{array}{l}\text { Serum chol. } \\
\text { and E Eobol } \\
\text { (\% body wt) }\end{array}$ & $\begin{array}{l}\text { Serum chol. } \\
\text { and Eohol } \\
\left(/ \mathrm{m}^{2} \mathrm{BSA}\right)\end{array}$ & $\begin{array}{l}\text { Serum chol. } \\
\text { and } t_{t} \text { chol. }\end{array}$ & $\begin{array}{c}t_{y} \text { chol. } \\
\text { and Eobol } \\
(\% \text { body wt) }\end{array}$ & 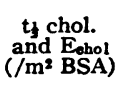 \\
\hline $\begin{array}{l}r \\
p\end{array}$ & $\begin{array}{r}+0.23 \\
0.47\end{array}$ & $\begin{array}{r}+0.20 \\
0.54\end{array}$ & $\begin{array}{r}+0.38 \\
0.23\end{array}$ & $\begin{array}{r}+0.32 \\
0.31\end{array}$ & $\begin{array}{r}+0.24 \\
0.45\end{array}$ \\
\hline
\end{tabular}

${ }^{*} \mathrm{r}=$ Correlation coefficient $; \mathrm{p}=$ probability. 


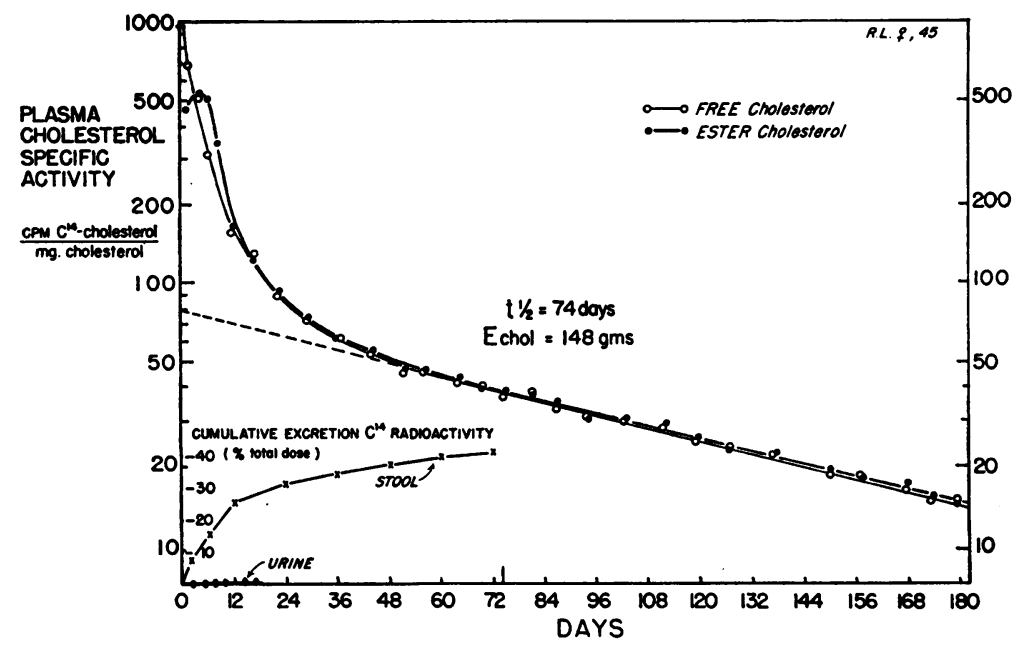

Fig. 1. The disappearance of plasma Cholesterol SPECIFIC ACtivity AND THE CUMULATIVE STOOL AND URINARY EXCRETION OF $C^{14}$ RADIOACTIVITY AFTER THE INTRAVENOUS ADMINISTRATION OF $\mathrm{C}^{14}$-CHOLESTEROL.

In the group studied, the plasma free cholesterol specific activity reached a peak between 3 and 24 hours after labeled cholesterol administration whereas the ester cholesterol specific activity was maximal between the second and fourth days. The rate at which both free and ester cholesterol specific activities decreased was relatively rapid at first, with cholesterol specific activities at the end of 2 weeks generally less than 25 per cent of the peak plasma specific activities. From the third week to between the sixth and eighth weeks of the study, there was a gradually diminishing rate of decrease of cholesterol specific activity from the plasma. After the eighth week, until the termination of the study at 18 to 32 weeks, the decay curve of plasma cholesterol specific activity fell at a slow rate which remained exponential throughout the remainder of the study. The halftime disappearance $\left(t_{1}\right)$ of cholesterol was obtained graphically from the linear plot on a semilogarithmic scale of the slow component of the plasma free cholesterol specific activity curve. The miscible or exchangeable cholesterol (Eenol) was calculated by isotope dilution principles after extrapolation of this linear plot of the slow component of the specific activity curve to zero time (the time at which the labeled cholesterol was infused). In two patients the exchangeable cholesterol was also calculated from the plasma spe- cific activity and the retained dose of cholesterol (corrected for stool and urinary excretion but not for insensible skin loss) at a time when the rate of disappearance of plasma cholesterol specific activity was exponential. The amount of cholesterol turned over per day was calculated from the equation:

$$
\text { daily cholesterol turnover }=\frac{0.693}{t_{1}} \times E_{\text {chol }}
$$

The free and ester cholesterol specific activities were generally similar from the fifth day of the study until its end, although the ester cholesterol specific activity was usually slightly greater than the free specific activity.

2. Cholesterol miscible pool. The cholesterol miscible pool values of all individuals studied averaged 0.27 per cent and ranged from 0.18 to 0.35 per cent of body weight. In the hypercholesterolemic patients the $E_{\text {chol }}$ averaged 0.29 per cent and ranged from 0.19 to 0.35 per cent body weight as compared with a mean of 0.24 and a range of 0.18 to 0.28 per cent in the normal group. No significant correlation was present between the serum cholesterol and miscible pool of cholesterol. Both of the patients with the nephrotic syndrome and the one patient with myxedema had $\mathrm{E}_{\text {chol }}$ values which were in the normal range despite markedly elevated serum cholesterol levels. The patient 
with familial hypercholesterolemia had the greatest $\mathrm{E}_{\mathrm{chol}}$ level in the group.

In Patient R.L. the $E_{\text {chol }}$ as calculated from the retained dose and plasma specific activity of cholesterol on day 60 was $154 \mathrm{~g}$, compared with $148 \mathrm{~g}$ as calculated by extrapolating the exponential portion of the plasma specific activity curve. In Patient H.L. $E_{\text {chol }}$ values of 202 and $193 \mathrm{~g}$, respectively, were obtained by the two methods of calculation.

The xanthelasmata of the patient with familial hypercholesterolemia had a specific activity that was 96 per cent of the plasma cholesterol specific: activity 62 days after labeled cholesterol administration. The skin overlying the xanthelasmata in this patient had a cholesterol specific activity that was 102 per cent of the plasma cholesterol specific activity, indicating that complete equilibration between skin and plasma cholesterol was present at 62 days.

3. Cholesterol turnover rate. The half-time disappearance of cholesterol averaged 72 days and ranged from 58 to 100 days in the 12 patients studied. The calculated amount of exchangeable cholesterol turned over per day averaged 1.9 and ranged from 1.0 to $3.2 \mathrm{~g}$. The $t_{1}$ of the normal subjects averaged 65 days and ranged from 58 to 75 days, as compared with a mean $t_{1}$ of 76 days and range of 63 to 100 days in the hypercholesterolemic group. The patient with myxedema had the slowest turnover rate of cholesterol, with a $t_{\frac{1}{2}}$ of 100 days. The remaining $t_{1}$ values of the hypercholesterolemic subjects were comparable to the values observed in the normal group. No significant correlation was present between the concentration of serum cholesterol and the turnover rate of cholesterol or between the size of the miscible pool and the turnover rate of cholesterol.

4. Stool and urinary excretion of $C^{14}$ radioactivity. The stool excretion of total $\mathrm{C}^{14}$ radioactivity was greatest during the first week of the study and gradually decreased with time. In Patient R.L. (Figure 1), 43 per cent of the total injected $\mathrm{C}^{14}$ radioactivity was recovered in the stools during the first 72 days after labeled cholesterol administration. In the first 15 days the total urinary excretion of $\mathrm{C}^{14}$ radioactivity was 0.2 per cent of the injected dose with no measurable radioactivity present after the fifth day of

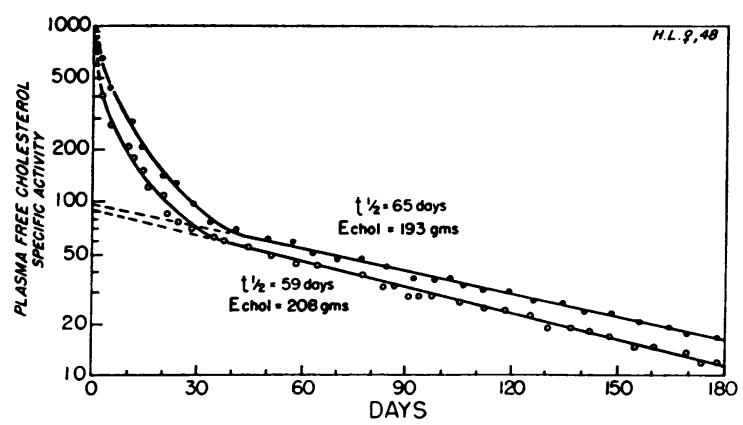

Fig. 2. The disappearance of plasma cholesterol SPECIFIC ACTIVITY AFTER THE INTRAVENOUS ADMINISTRATION OF $\mathrm{C}^{14}$-CHOLESTEROL IN A SUBJECT STUDIED TWICE AT A YEARLY INTERVAL.

study. The combined stool and urinary excretion of $\mathrm{C}^{14}$ radioactivity accounted for approximately 88 per cent of the labeled cholesterol turned over per day as calculated from the $t_{1}$ value of 74 days which was measured from the plasma specific activity decay curve.

In Patient H.L. 45 per cent of the injected $\mathrm{C}^{14}$ radioactivity was present in the stools over the first 65 days after cholesterol administration while 0.1 per cent of the total dose was recovered in the urine over the first 15 days. The total stool and urinary excretion of radioactivity represented approximately 82 per cent of the total labeled cholesterol turned over as calculated from the $t_{\frac{1}{2}}$ value of 59 days.

5. Reproducibility of studies. Repeat measurements of cholesterol turnover rate and miscible pool in Subjects H.L. and R.M. after 12 and 14 months, respectively, gave results similar to those obtained in the original studies of these patients. In Subject H.L. (see Figure 2), the half-time disappearance of cholesterol was 59 and 65 days and in R.M. 78 and 85 days, respectively. The $E_{\text {ehol }}$ in H.L. was $193 \mathrm{~g}$ in the first and $208 \mathrm{~g}$ in the second study, and in Subject R.M. values of 201 and $215 \mathrm{~g}$, respectively, were obtained.

\section{DISCUSSION}

The rate of disappearance from the plasma of $\mathrm{C}^{14}$-labeled cholesterol has been studied extensively over varying intervals (3-7). However, greatly differing turnover times for cholesterol have been reported, ranging from $t_{1}$ values of 5 to 110 days, 
depending upon the length of time the studies were carried out and the portion of the plasma specific activity curve used to calculate the turnover rates. To explain the varying turnover rates which have been reported, Hellman, Rosenfeld and Gallagher have pointed out that, over periods of as long as 50 days, the cholesterol may disappear from the plasma at a series of exponential rates rather than at a single one so that no true body turnover rate could be expressed from the plasma disappearance curves during this period (3). Their studies have been confirmed by Kurland, Lucas and Freedberg (4) and by the present investigation. Both of these latter studies have also demonstrated that if the plasma cholesterol specific activity is followed over longer periods, its curve of disappearance eventually does decline at an exponential rate. An explanation of why a prolonged period of study is necessary for measurement of a true body turnover rate of cholesterol is obtained from the post-mortem studies concerning the equilibration of cholesterol between the plasma and tissues (5). These studies have shown that this equilibration is generally a slow process and does not approach completion for periods of a month or more in some of the exchanging tissue compartments. Thus, the decrease of $\mathrm{C}^{14}$-cholesterol from the plasma prior to the time when complete equilibration with the tissues was attained would reflect the continuing distribution of cholesterol between the blood and tissues as well as the metabolic turnover of cholesterol within the miscible pool. In view of the similar cholesterol specific activities in the plasma and tissues from 1 to 7 months after labeled cholesterol administration and the exponential rate of decay of plasma cholesterol specific activity during this same interval, it appears that an equilibrium state between the plasma and tissue cholesterol persists during this period. For these reasons, a portion of the plasma decay curve extending from the period beginning 6 to 8 weeks after labeled cholesterol administration to the end of the study at approximately 18 to 32 weeks was used to calculate the body turnover rate and miscible pool of cholesterol.

The cholesterol turnover rates varied from $t_{1}$ values of 58 to 100 days. In this heterogeneous group of patients with hypercholesterolemia, the mean $t_{1}$ was somewhat greater than that in the normal individuals. The slowest turnover rate of cholesterol was found in the myxedematous patient. However, with the exception of this patient, the $t_{2}$ values of the hypercholesterolemic individuals were generally within the normal range. A slow turnover rate of cholesterol in myxedema has been described previously (4) and may reflect a decrease in the rate of biliary and stool excretion of cholesterol and its degradation products (8).

The cholesterol miscible pool ranged from 125 to $349 \mathrm{~g}$ or 0.18 to 0.35 per cent of body weight. These values are comparable to those reported from actual carcass analysis in other mammals including the mouse, rat, cat, and dog (9-12). No significant correlation between the serum cholesterol and the exchangeable cholesterol was apparent from this study, although the hypercholesterolemic group did have a greater mean $E_{\text {chol }}$ level than had the normal subjects. The differences in $E_{c h o l}$ values in the hypercholesterolemic group might be a reflection of different etiological factors causing elevations in serum cholesterol in these individuals. The patients with myxedema and the nephrotic syndrome had values for $E_{\text {chol }}$ which were in the normal range despite marked elevations in serum cholesterol, suggesting perhaps that the hypercholesterolemia in these conditions is associated with a shift of cholesterol from extravascular to intravascular compartments. On the other hand, the remaining hypercholesterolemic subjects did have $E_{\text {chol }}$ values which were generally greater than those observed in the normal group, indicating that in some individuals elevations in serum cholesterol level may reflect an elevated body cholesterol content. The number of patients studied to date has been limited so that further observations will be necessary before other conclusions regarding the relationship of serum and body cholesterol can be established.

It is interesting that the greatest miscible pool of cholesterol was observed in the patient with familial hypercholesterolemia and xanthelasmata. The cholesterol in the xanthelasmata appears to be a part of the miscible pool of cholesterol, and the presence of these subcutaneous deposits of cholesterol may be a reflection of a high $\mathrm{E}_{\text {chol }}$ level.

The total amount of exchangeable cholesterol 
that was turned over per day in these subjects ranged from 1.0 to $3.2 \mathrm{~g}$ daily. Stool and urinary excretion of $\mathrm{C}^{14}$ radioactivity accounted for 82 and 88 per cent of the calculated daily turnover of cholesterol in the two patients in whom these collections were made. Skin secretion of cholesterol, which represents one other significant source of sterol loss from the body was not measured in these patients, but it is estimated that 50 to $100 \mathrm{mg}$ of cholesterol is secreted by the skin per day $(13,14)$. This would represent approximately 3 to 7 per cent of the calculated daily turnover of exchangeable cholesterol in these two individuals, and if this estimated skin loss were added to the measured stool and urinary losses, the total would appear to account for approximately 90 per cent of the cholesterol turned over per day as calculated from the plasma cholesterol specific activity curves. These findings lend further support to the hypothesis that a body turnover rate of cholesterol is measured by these plasma disappearance curves.

As has been reported previously, the $\mathrm{C}^{\mathbf{1 4}}$ radioactivity that is administered in the form of labeled cholesterol appears to remain in the body mainly as a part of the cholesterol molecule $(4,15)$. In the stool, however, most of this cholesterol is excreted in the form of bile acids (16).

The miscible pool of cholesterol that has been measured in this study appears to include the cholesterol in all the body tissues outside of the central nervous system. It had been shown previously that only negligible degrees of equilibration occur between the plasma and brain cholesterol during the interval used in these studies (4). Since about 20 per cent of the total body sterol is estimated to be in the nervous system (17), it appears that the miscible pool of cholesterol would constitute approximately 80 per cent of total body cholesterol.

\section{SUMMARY AND CONCLUSIONS}

1. Measurements of body cholesterol miscible pool and turnover rate have been carried out in normal and hypercholesterolemic subjects by studying the rate of disappearance of $\mathrm{C}^{14}$-cholesterol specific activity from the plasma over periods of 4 to 7 months after the intravenous administration of labeled cholesterol.

2. The miscible pool of cholesterol measured by these methods ranged from 0.18 to 0.35 per cent of body weight in 12 human subjects. The level of the cholesterol miscible pool did not correlate significantly with the serum cholesterol level.

3 . The body turnover rate of cholesterol ranged from half-time values of 58 to values of 101 days, and the total amount of exchangeable cholesterol turned over per day ranged from 1.0 to $3.2 \mathrm{~g}$.

4. Patients with idiopathic and familial hypercholesterolemia had exchangeable cholesterol values above the normal range.

5. Most hypercholesterolemic patients had halftime values for cholesterol within the normal range, but a patient with myxedema appeared to have a markedly reduced body cholesterol turnover rate.

\section{ACKNOWLEDGMENTS}

The authors are indebted to Drs. A. Stone Freedberg and George Kurland for their advice and to Dr. Herbert Wotiz for his assistance in measuring the $\mathrm{C}^{14}$ radioactivity of the stool specimens.

\section{REFERENCES}

1. Moore, F. D. Determination of total body water and solids with isotopes. Science 1946, 104, 157.

2. Stetten, DeW., Jr. On the metabolic defect in gout. Bull. N. Y. Acad. Med. 1952, 28, 664.

3. Hellman, L., Rosenfeld, R. S., and Gallagher, T. F. Cholesterol synthesis from C-14 acetate in man. J. clin. Invest. 1954, 33, 142.

4. Kurland, G. S., Lucas, J. L., and Freedberg, A. S. The metabolism of intravenously infused $\mathrm{C}^{14}$-labeled cholesterol in euthyroidism and myxedema. J. Lab. clin. Med. 1961, 57, 574.

5. Chobanian, A. V., and Hollander, W. Body cholesterol metabolism in man. I. The equilibration of serum and tissue cholesterol. J. clin. Invest. 1962, 41, 1732.

6. Biggs, M. W., Kritchevsky, D., Colman, D., Gofman, J. W., Jones, H. B., Lindgren, F. T., Hyde, G., and Lyon, T. P. Observations on the fate of ingested cholesterol in man. Circulation 1952, 6, 359.

7. LeRoy, G. V. Studies of cholesterol synthesis in man using carbon ${ }^{14}$ labeled acetate. Ann. intern. Med. 1956, 44, 524.

8. Rosenman, R. H., Byers, S. O., and Friedman, M. The mechanism responsible for the altered blood cholesterol content in deranged thyroid states. J. clin. Endocr. 1952, 12, 1287. 
9. Schoenheimer, R., and Breusch, F. Synthesis and destruction of cholesterol in the organism. J. biol. Chem. 1933, 103, 439.

10. Channon, H. J. Cholesterol synthesis in the animal body. Biochem. J. 1925, 19, 424.

11. Beumer, H., and Lehmann, F. Über die Cholesterenbildung im Tierkörper für du gasamte. Z. ges. exp. Med. 1923, 37, 274.

12. Menschick, W., and Page, I. H. Der Abbau des Cholesterins durch den tierischen Organismus. II. Mitteilung. Bilanzversuche an Carnivoren bei starker Cholesterinfütterung. Z. physiol. Chem. 1933, 218, 95.

13. Cook, R. P. Comparative Aspects of Lipid Absorption and Excretion. Biochem. Soc. Symposium 1952, 9, 14.
14. Boughton, B., MacKenna, R. M. B., Wheathy, V. R., and Wormall, A. Studies of sebum. 8. Observations on the squalene and cholesterol content and the possible functions of squalene in human sebum. Biochem. J. 1957, 66, 32.

15. Hellman, L., Rosenfeld, R. S., Eidinoff, M. L., Fukushima, D. K., Gallagher, T. F., Wang, C. I. and Adlersberg, D. Isotopic studies of plasma cholesterol of endogenous and exogenous origin. J. clin. Invest. 1955, 34, 48.

16. Sipirstein, M. D., and Chaikoff, I. L. Conversion of cholesterol to bile acids. Fed. Proc. 1955, 14, 767.

17. Cook, R. P. Cholesterol. Chemistry, Biochemistry, and Pathology. New York, Academic Press, 1958, p. 174. 